Research Article

\title{
A Descriptive Study to Assess the Prevalence of Nomophobia among School going Children in Selected Districts of Gujarat
}

\author{
$\underline{\text { Binu Joe', }} \underline{\text { Linson } \mathrm{CC}^{2}}$ \\ ${ }^{1} \mathrm{PhD}$ Scholar, SRK University, Bhopal, MP, India. \\ 2JOSCO, Mangalore. \\ DOI: https://doi.org/10.24321/2348.2133.202004
}

\section{I $\quad \mathbf{N} \quad \mathbf{F} \quad \mathbf{O}$}

\section{Corresponding Author:}

Binu Joe, SRK University, Bhopal, MP, India.

E-mail Id:

binu_joe@rediffmail.com

Orcid Id:

https://orcid.org/0000-0002-7377-6593

How to cite this article:

Joe B, Linson CC. A Descriptive Study to Assess the Prevalence of Nomophobia among School going Children in Selected Districts of Gujarat. Ind J Holist Nurs 2020; 11(4): 1-4.

Date of Submission: 2020-11-22

Date of Acceptance: 2020-12-17
$\begin{array}{llllllll}\mathbf{A} & \mathbf{B} & \mathbf{S} & \mathbf{T} & \mathbf{R} & \mathbf{A} & \mathbf{C} & \mathbf{T}\end{array}$

Introduction: Mobile phones have nowadays become a part and parcel of our life. We are not able to live without mobile technology. Mobiles have become an important part of our techno culture. Adolescents are very used to mobile phones and they are not able to live without them. Smartphones are the basic necessity of an adolescent's life.

Method: A descriptive study was conducted to assess the prevalence of nomophobia among school-going children from Rajkot and Surendranagar districts of Gujarat.

Result: The present study reveals that $52.58 \%$ of the participants had a moderate level of nomophobia, $32.58 \%$ had a mild level of nomophobia, $14.40 \%$ had a severe level of nomophobia, and only $0.44 \%$ had no signs of nomophobia.

Conclusion: In the present scenario, due to online classes, students are more and more involved with smartphone technologies for online classes. Nomophobia is very prevalent among school-going children and it's affecting their health.

Keywords: Prevalence, Descriptive Study, Nomophobia, School Going Children

\section{Introduction}

Nomophobia is a new medical term that is defined as the fear of being without a mobile phone. Nomophobia is very common, especially among teenagers. Anxious of losing their mobile phones, mobile phones running out of battery, mobile phones without any network coverage are the fears common among teenagers. Nomophobic people never switch off their mobile phones. They use their mobile phones in bed and are never separated from their phones. Students suffering from nomophobia may carry an extra phone with them. They don't allow their mobile phones to be used by another person and never allow anyone to see their mobile phones. Nomophobic persons are not able to concentrate on academics and their regular works. They have disturbed family relationships.

\section{Objectives of the Study}

- To assess the prevalence of nomophobia among schoolgoing children

- To find the association between the prevalence of nomophobia among school-going children with the selected demographic variables

\section{Review of Literature}

The use of smartphones and mobiles is ever-increasing 
and is taking a toll especially on the health of teenagers. Social and psychological problems are also very common among adolescents. The term nomophobia is defined as the "No Mobile Phone Phobia". This is also known as the fear of being out of mobile phone contact. There are various studies that mainly focus on the students' populations since the younger generation is more dependent on technology and they are very technology savvy. Mobile phones have led to a decrease in the quality and quantity of time spent by the family members with each other. The adolescent generation is more dependent on mobile phone technology. This structured questionnaire-based study is mainly aimed to know the prevalence rate of nomophobia among adolescents groups. This study especially focuses on adolescents as they are more prone to nomophobia among the general group of population.

Nomophobia is especially rising during this current COVID-19 pandemic. Online classes are very common during this pandemic, and this is a major cause of the increasing cases of nomophobia.

\section{Research Methodology}

A descriptive research approach was used to find the prevalence of nomophobia among school-going children in the selected districts of Gujarat from August 2020 to September 2020. A structured nomophobia questionnaire was used to assess the prevalence of nomophobia among school-going children. Total 1145 school going children were selected from five different schools of Rajkot and Surendranagar district of Gujarat through convenience sampling technique. The responses were tabulated and analysed.

\section{Research Setting}

The study was carried out in the five different schools of Rajkot and Surendranagar district of Gujarat. 1145 participants were selected by convenience sampling technique. The study participants were selected based on the following criteria.

\section{Inclusion Criteria}

- Adolescents of standards 9th to 12th of selected schools

- Adolescents who were present at the time of data collection

\section{Exclusion Criteria}

- Adolescents not willing to participate in the study

- Adolescents who had some diseases and were not present during the period of data collection

\section{Tools Used for the Study}

Structured Demographic Performa: it consisted of age, gender, year of study, type of family, religion, number of mobile phones being used, duration of using mobile phones, frequency of using mobile phones, money spent on mobile phones every month, family monthly income, awareness of the term nomophobia.

Structured Nomophobia Questionnaire (NMP-Q): Structured Nomophobia questionnaire was prepared by Yildrim, which consists of standard 20 questionnaire items. These 20 items were used in the study to measure the degree of mobile dependence among ] adolescents. The tool was structured based on Likert scale pattern. Seven point Likert scales was used for the present study. The total score on the NMP-Q is 20 at its lowest $(20 * 1)$ or $140(20 * 7)$ at its highest. The adolescents have to mark from 1 to 7 in the various items. Score 1 strongly disagree, followed by disagree, somewhat disagree, neutral, somewhat agree, agree, and strongly agree being the highest with a score of seven. The interpretation of the tool was done as shown in Table 1.

Table I.Score and Interpretation of Structured Nomophobia Questionnaire

\begin{tabular}{|c|c|}
\hline Score & Interpretation \\
\hline 20 & Absence of nomophobia \\
\hline $21-59$ & Mild level of nomophobia \\
\hline $60-99$ & Moderate level of nomophobia \\
\hline $100-140$ & Severe nomophobia \\
\hline
\end{tabular}

The main study was carried out from 01/09/2020 to 08/09/2020. Prior permission and ethical clearance were taken from the institution and study participants.

\section{Result}

Table 2.Distribution of Demographic Characteristics

$(n=1145)$

\begin{tabular}{|c|c|c|}
\hline Demographic Characteristics & Number & Percentage \\
\hline \multicolumn{3}{|c|}{ Age (in years) } \\
\hline $13-15$ & 663 & 57.90 \\
\hline $16-18$ & 482 & 42.10 \\
\hline \multicolumn{3}{|c|}{ Gender } \\
\hline Male Standard & 581 & 50.74 \\
\hline Female & 317 & 27.69 \\
\hline $9^{\text {th }}$ & 495 & 43.23 \\
\hline $10^{\text {th }}$ & 181 & 15.81 \\
\hline $11^{\text {th }}$ & 152 & 13.27 \\
\hline $12^{\text {th }}$ & 688 & 60.09 \\
\hline \multicolumn{3}{|c|}{ Type of family } \\
\hline Nuclear & 457 & 39.91 \\
\hline Joint &
\end{tabular}




\begin{tabular}{|c|c|c|}
\hline \multicolumn{3}{|c|}{ Religion } \\
\hline Hindu & 988 & 86.29 \\
\hline Christian & 80 & 6.99 \\
\hline Muslim & 48 & 4.19 \\
\hline Others & 29 & 2.53 \\
\hline \multicolumn{3}{|c|}{ Number of mobile phones being used per person } \\
\hline 1 & 899 & 78.52 \\
\hline 2 & 161 & 14.06 \\
\hline 3 and above & 85 & 7.42 \\
\hline \multicolumn{3}{|c|}{ Duration of mobile phone usage (in years) } \\
\hline 1 & 1034 & 90.31 \\
\hline $2-3$ & 74 & 6.46 \\
\hline $4-5$ & 11 & 0.96 \\
\hline More than 6 & 26 & 2.27 \\
\hline \multicolumn{3}{|c|}{ Frequency of checking mobile phone in a day } \\
\hline Once & 93 & 8.12 \\
\hline 2-5 times & 655 & 57.21 \\
\hline More than 6 times & 397 & 34.67 \\
\hline \multicolumn{3}{|c|}{ Money spent per month on mobile recharge (in INR) } \\
\hline Less than 200 & 496 & 43.32 \\
\hline $200-400$ & 513 & 44.80 \\
\hline More than 400 & 136 & 11.88 \\
\hline \multicolumn{3}{|c|}{ Duration of using mobile phone per day } \\
\hline Less than 30 minutes & 1103 & 96.33 \\
\hline 30 minutes to 1 hour & 26 & 2.27 \\
\hline More than 1 hour & 16 & 1.40 \\
\hline \multicolumn{3}{|c|}{ Family monthly income (in INR) } \\
\hline Below 10000 & 83 & 7.25 \\
\hline $10000-15000$ & 262 & 22.88 \\
\hline $15001-20000$ & 142 & 12.40 \\
\hline Above 20000 & 658 & 57.47 \\
\hline \multicolumn{3}{|c|}{ Awareness of the term nomophobia } \\
\hline Yes & 1056 & 92.23 \\
\hline No & 89 & 7.77 \\
\hline
\end{tabular}

Majority (57.90\%) of the school-going children were in the age group of 13 to 15 years. $50.74 \%$ of the participants were males. Maximum (43.23\%) participants were studying in the 10th standard. Most (60.9\%) of the school-going children belonged to nuclear families. $86.29 \%$ of the participants belonged to the Hindu religion. $78.52 \%$ were using one mobile phone. Most of them (90.31\%) were using mobile phones for the last one year. $57.21 \%$ used to check their mobile phones 2 to 5 times a day. Approximately, the same number of children, $44.80 \%$ and $43.32 \%$, used to spend 200 to 400 INR every month on mobile recharge and less than 200 INR respectively. Maximum (96.33\%) participants used to speak for less than 30 minutes over the mobile phone. $57.47 \%$ of the participant's monthly family income was above 20000 INR per month. Most (92.23\%) of the participants had some knowledge related to nomophobia.

Prevalence of nomophobia measured as per the standard nomophobia questionnaire revealed that only $0.44 \%$ of the participants had no nomophobia. $52.58 \%$ of the school-going children had a moderate level of nomophobia. $32.58 \%$ had a mild level of nomophobia, followed by $14.40 \%$ of the school-going children who had a severe level of nomophobia.

Table 3.Prevalence of Nomophobia among Adolescents

\begin{tabular}{|c|c|c|}
\hline Prevalence of Nomophobia & Number & Percentage \\
\hline $\begin{array}{c}\text { Absence } \\
(0-20)\end{array}$ & 5 & 0.44 \\
\hline $\begin{array}{c}\text { Mild level } \\
(21-59)\end{array}$ & 373 & 32.58 \\
\hline $\begin{array}{c}\text { Moderate level } \\
(60-99)\end{array}$ & 602 & 52.58 \\
\hline $\begin{array}{c}\text { Severe } \\
(100-140)\end{array}$ & 165 & 14.40 \\
\hline
\end{tabular}

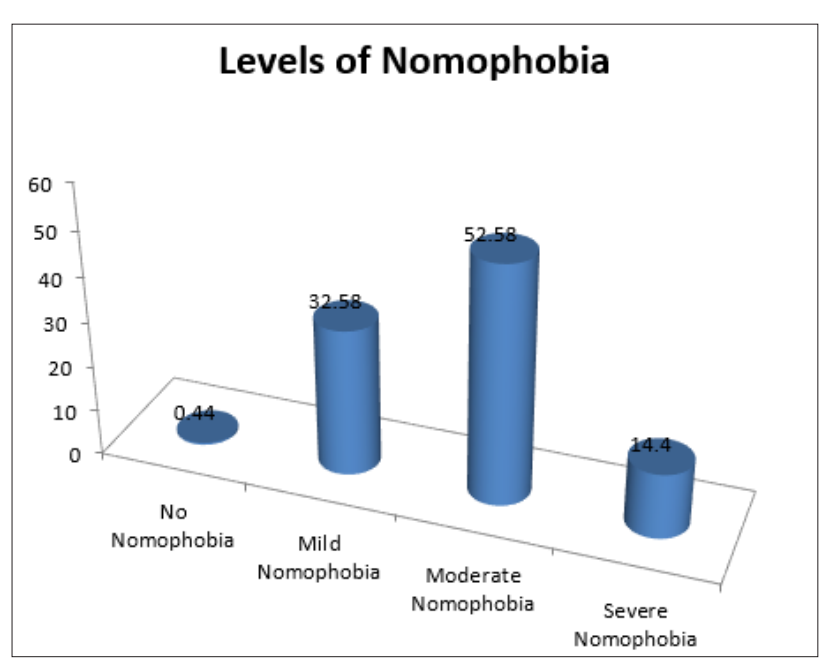

Figure I.Prevalence of Nomophobia among Schoolgoing Children

The analysis of association between the prevalence of nomophobia among adolescents with the selected demographic variables revealed that there was a significant association when compared with age, year of study, and amount of money spent every month on mobile recharge. There was no association found between nomophobia prevalence and the rest of the selected demographic variables. 
Table 4.Association between Post-test Knowledge Score on Nomophobia and its Prevention with the Selected Demographic Variables

$(n=1145)$

\begin{tabular}{|c|c|c|}
\hline Demographic Characteristics & Chi-square Value & P-value \\
\hline Age & $18.8 \mathrm{~S}$ & $\mathrm{P}<0.05 \mathrm{df}=3$ \\
\hline Gender & $3.31 \mathrm{NS}$ & $\mathrm{P}>0.05, \mathrm{df}=3$ \\
\hline Year of study & $75.9 \mathrm{~S}$ & $\mathrm{P}<0.05, \mathrm{df}=9$ \\
\hline Type of family & $3.68 \mathrm{NS}$ & $\mathrm{P}>0.05, \mathrm{df}=3$ \\
\hline Religion & $16.7 \mathrm{NS}$ & $\mathrm{P}>0.05, \mathrm{df}=9$ \\
\hline Number of mobile phones being used & $2.04 \mathrm{NS}$ & $\mathrm{P}>0.05, \mathrm{df}=9$ \\
\hline Duration of mobile phone usage & $14.3 \mathrm{NS}$ & $\mathrm{P}>0.05, \mathrm{df}=6$ \\
\hline Frequency of checking mobile phones & $1.27 \mathrm{NS}$ & $\mathrm{P}<0.05, \mathrm{df}=6$ \\
\hline Amount of money spent every month on mobile recharge & $13.7 \mathrm{~S}$ & $\mathrm{P}>0.05, \mathrm{df}=6$ \\
\hline Duration of conversation over mobile phones per day & $7.06 \mathrm{NS}$ & $\mathrm{P}>0.05, \mathrm{df}=6$ \\
\hline Family monthly income & $9.13 \mathrm{NS}$ & $\mathrm{P}>0.05, \mathrm{df}=3$ \\
\hline Awareness of the term nomophobia & $1.88 \mathrm{NS}$ & \\
\hline
\end{tabular}

*Significant at 5\% Level, NS: Non-significant.

\section{Discussion}

The findings of the study clearly reveal that nomophobia is highly prevalent among school-going children. $52.58 \%$ of the participants had a moderate level of nomophobia. $32.58 \%$ had a mild level of nomophobia, $14.40 \%$ had a severe level of nomophobia, and only $0.44 \%$ had no signs of nomophobia. There was also a significant association between the prevalence of nomophobia and demographic variables of age, year of study, and amount of money spent every month on mobile phone recharge.

\section{Source of Funding: None}

\section{Conflict of Interest: None}

\section{References}

1. Chandak P, Singh D, Faye A, Gawande S, Tadke R, Kirpekar $V$, Bhave S. An exploratory study of nomophobia in post graduate residents of a teaching hospital in central India. Int J Indian Psychol 2017; 4: 48-56.

2. Mandeep K, Maheshwari SK, Anil K. Compulsive buying behavior and online shopping addiction among health science teachers. Int J Nurs Care 2019; 7: 74-9. [Google Scholar]

3. Maheshwari SK, Preksha S. Internet addiction: A growing concern in India. Indian J Psychiatr Nurs 2018; 15: 61-8. [Google Scholar]

4. Pavithra MB, Suwarna M, Mahadeva Murthy TS. A study on nomophobia - Mobile phone dependence, among students of a medical college in Bangalore. Natl J Community Med 2015; 6: 340-4. [Google Scholar]

5. Gezgin D, Cakir O, Yildirim S. The relationship between levels of nomophobia prevalence and internet addiction among high school students: The factors influencing Nomophobia. Int J Res Educ Sci 2018; 4: 215-25. [Google Scholar]

6. Gezgin D, Sumuer E, Arslan O, Yildirim S. Nomophobia prevalence among pre-service teachers: A case of Trakya University. Trakya Univ J Educ Fac 2017; 7: 2504-19. [Google Scholar] 